\title{
Supplement of SOC sequestration potentials for agricultural management practices under climate change
}

\author{
Tobias Herzfeld ${ }^{1}$, Jens Heinke ${ }^{1}$, Christoph Müller ${ }^{1}$, Susanne Rolinski ${ }^{1}$
}

${ }^{1}$ Potsdam Institute for Climate Impact Research, Member of the Leibniz Association, P.O. Box 6012 03, 14412 Potsdam, Germany.

Correspondence: Tobias Herzfeld (tobias.herzfeld@pik-potsdam.de)

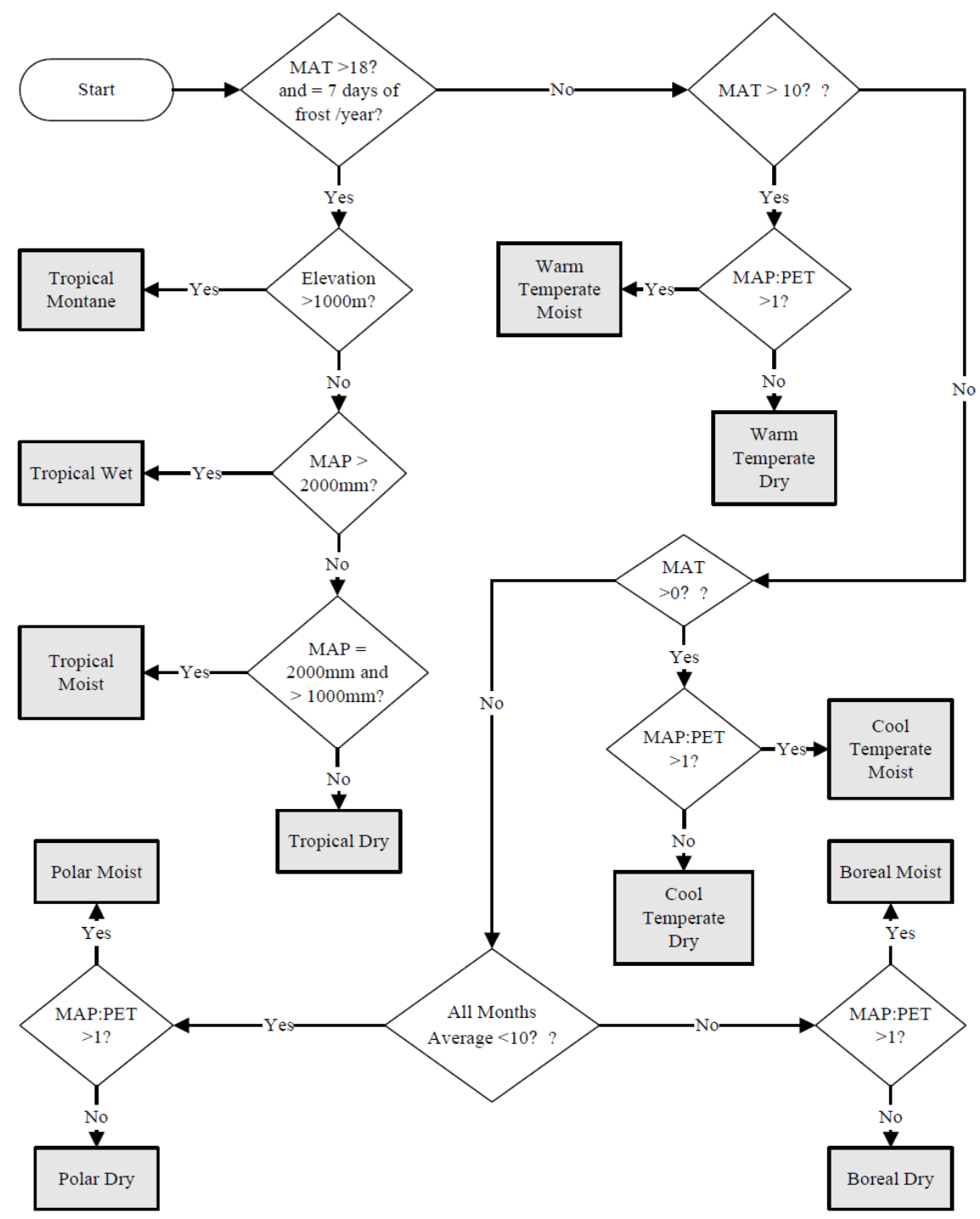

Figure S1

Climate region classification scheme according to the IPCC (2006). Polar moist, polar dry and tropical montane regions have been excluded from this analysis, as these are regions without cropland. 
(A)

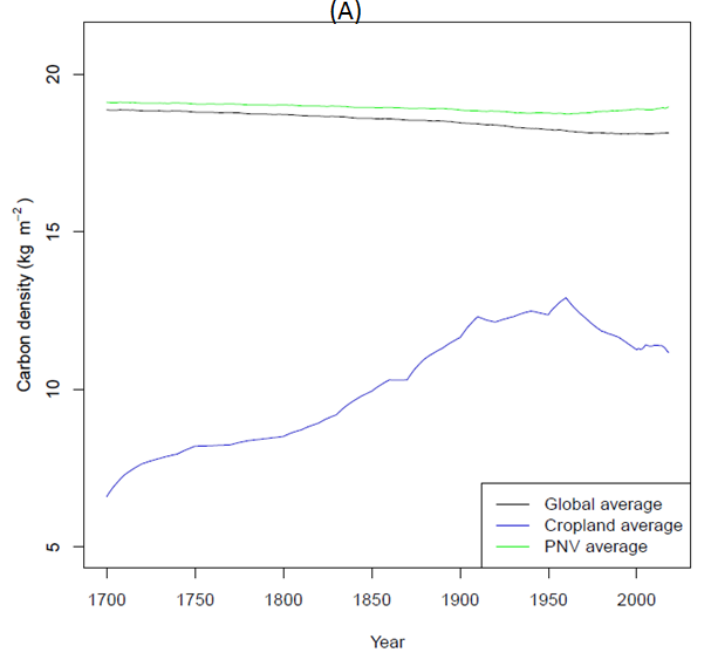

(B)

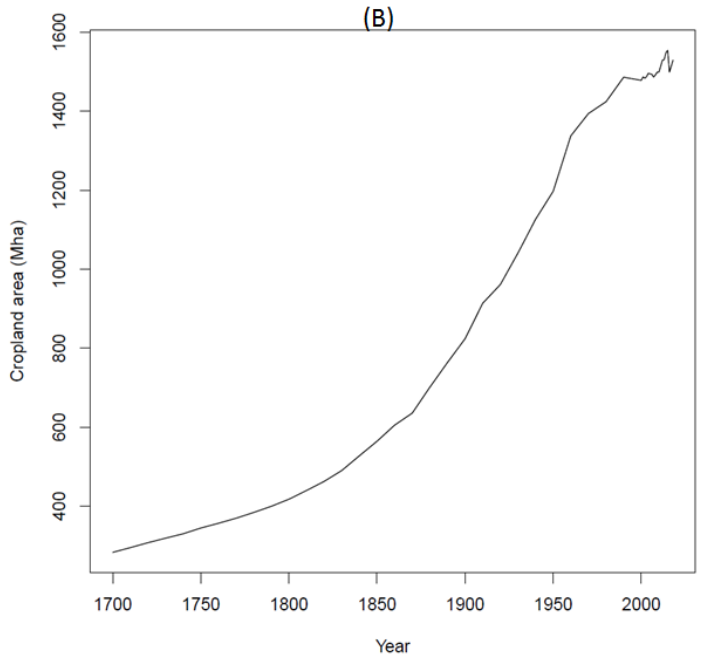

\section{Figure S2}

Time series of carbon density $\left(\mathrm{kg} \mathrm{m}^{-2}\right)$ of global average, cropland average and PNV average from year 1700 to 2018 (A) and global cropland area in million hectares (Mha) from year 1700 to 2018 (B). Cropland carbon densities increase as long as the addition of new high-carbon density land through land expansion outbalances the slow decline of SOC stocks on existing cropland. 
(A)

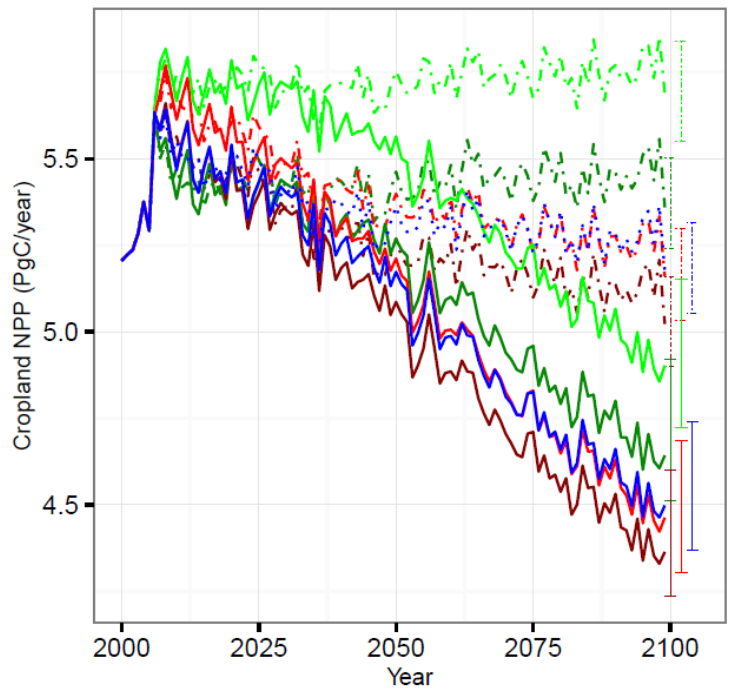

(C)

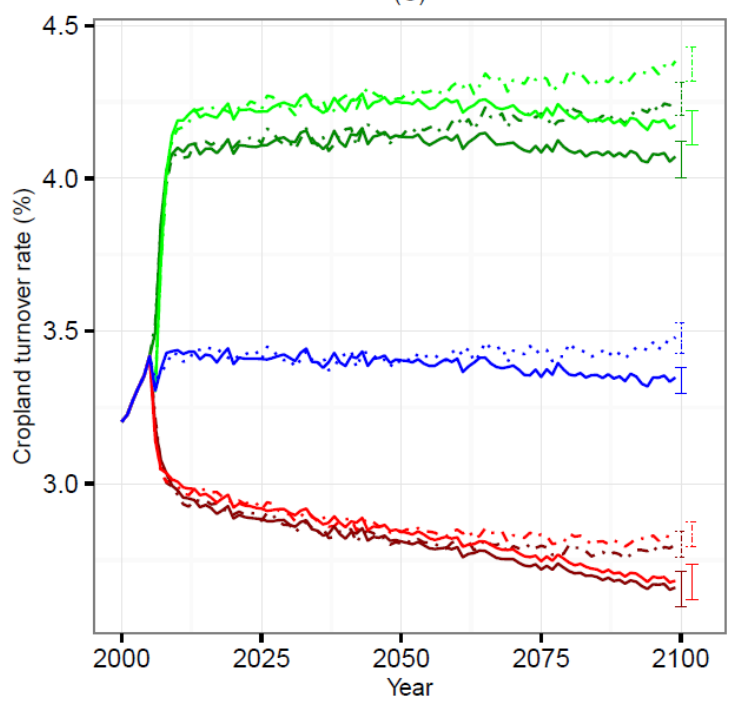

(B)

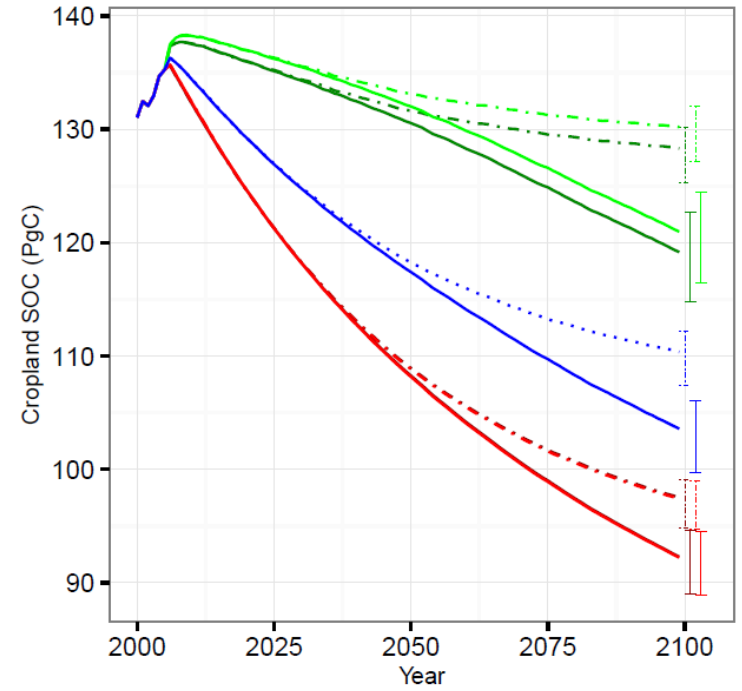

(D)

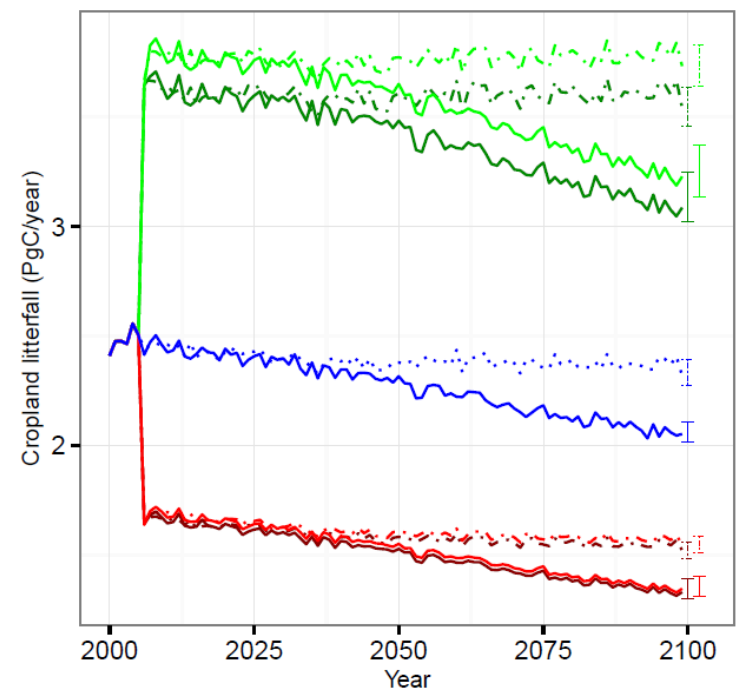

- NT_NR_26 - - NT_R_26 - T_NR_26 - T_R_26 $\cdots$ TRc05_26
- NT_NR_85 - NT_R_85 - T_NR_85 - T_R_85 - TRc05_85

Figure S3

Global sums of cropland NPP (A), cropland SOC (B), cropland turnover time (C) and cropland litterfall (D) for cropland from 2000-2005 for default management inputs and from 2006-2099 under constant cropland area of 2005 for five different management scenarios as in Figure 3, but with constant $\left[\mathrm{CO}_{2}\right]$ level from 2005 until the end of the century (378.8 ppm). Same legend as in Figure 3.

In $\mathrm{RCP} 8.5,\left[\mathrm{CO}_{2}\right]$ is projected to increase to a level of more than $900 \mathrm{ppm}$ until then end of the century, while in $\mathrm{RCP} 2.6\left[\mathrm{CO}_{2}\right]$ it is assumed to be at $420 \mathrm{ppm}$ (Fig. A4 in the appendix). Results from simulations with constant $\left[\mathrm{CO}_{2}\right]$ over the entire simulation period between year 2006 and 2099 show that differences for cropland SOC as well as for cropland NPP between the two climate change scenarios become more prominent. Total global NPP with static $\left[\mathrm{CO}_{2}\right]$ is considerably smaller in RCP8.5 compared to RCP2.6 and decreases significantly until the end of the century in all management systems (Fig. A3A in the appendix). If production decreases in RCP8.5, inputs from residues into the soil also decrease with time and as a result cropland SOC stocks are lower and decrease compared to RCP2.6 (Fig. A3B in the appendix), while turnover rate is stable (Fig. A3C in the appendix). $\mathrm{RCP} 2.6$ with static $\left[\mathrm{CO}_{2}\right]$ shows higher SOC stocks compared to RCP8.5, as production is higher in a colder climate (compared to 
RCP8.5), while at the same time turnover rates are lower. This suggests that under standard $\mathrm{RCP}$ climate input assumptions, $\mathrm{CO}_{2}$ fertilization effects in RCP8.5 driven by increasing $\left[\mathrm{CO}_{2}\right]$ compensate for damages from warmer climates and increases in turnover rates in order to sustain NPP. These compensating effects result in the small differences between the RCP2.6 and RCP8.5 found in this analysis.

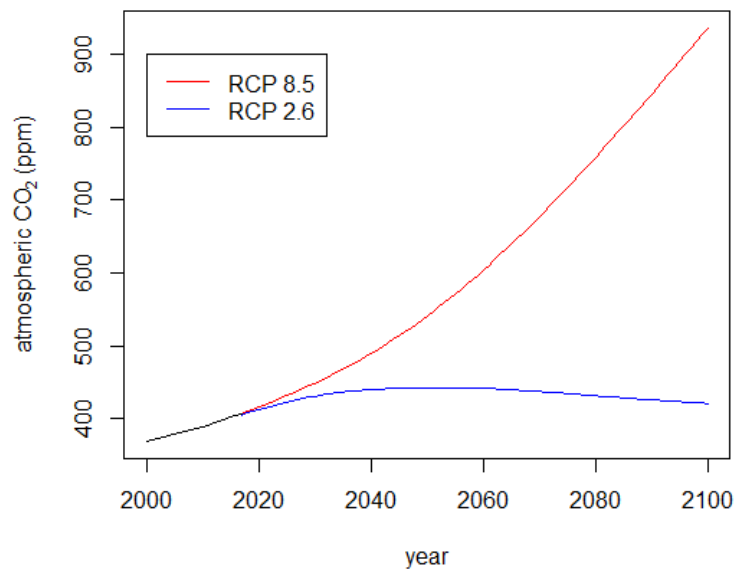

\section{Figure S4}

Atmospheric $\mathrm{CO}_{2}$ concentration input for model runs for RCP2.6 and RCP8.5. 

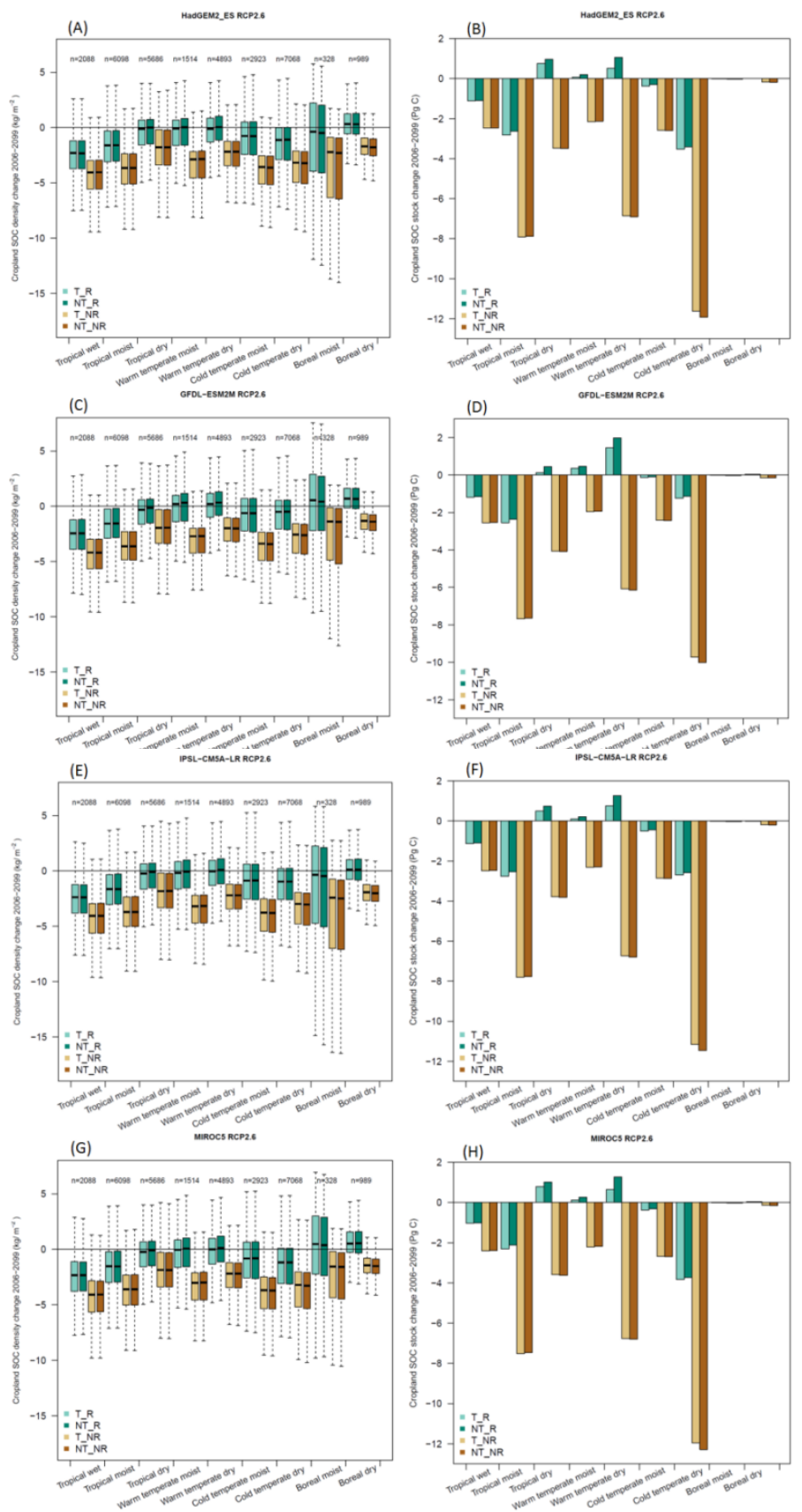

Figure S5

Boxplots of cropland SOC density change $\left(\mathrm{kg} / \mathrm{m}^{2}\right)$ and barplots of total cropland SOC change $(\mathrm{Pg}$ C) between year 2006 and 2099 for the four GCMs HadGEM2_ES (A,B), GFDL-ESM2M (C,D), IPSL-CM5A-LR (E,F), MIROC5 (G,H) in RCP2.6 for different climatic regions classified by the IPCC (2006) and the four management systems T_R, NT_R, T_NR and NT_NR. 

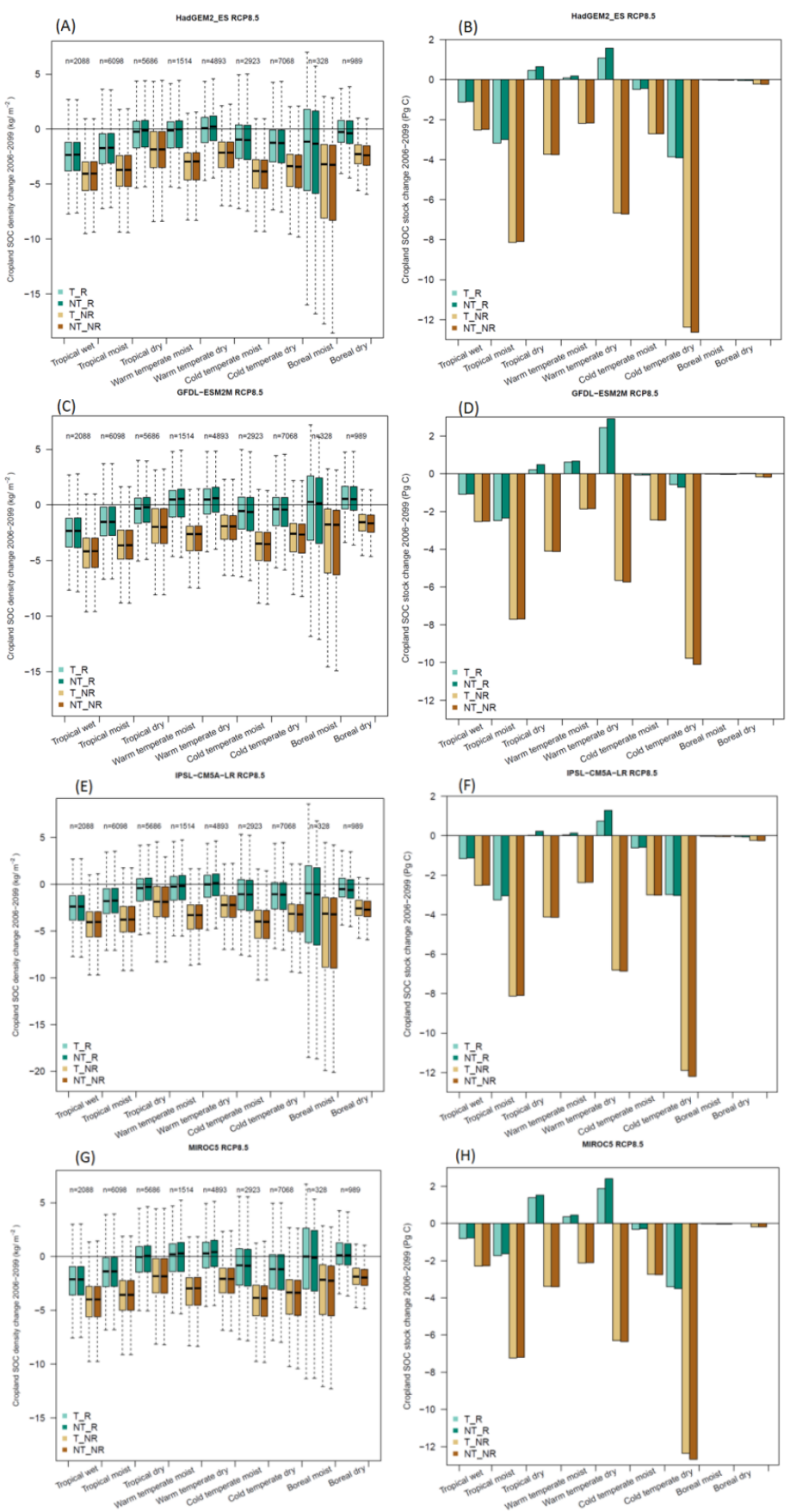

\section{Figure S6}

Boxplots of cropland SOC density change $\left(\mathrm{kg} / \mathrm{m}^{2}\right)$ and barplots of total cropland SOC change (Pg C) between year 2006 and 2099 for the four GCMs HadGEM2_ES (A,B), GFDL-ESM2M (C,D), IPSL-CM5A-LR (E,F), MIROC5 (G,H) in RCP8.5 for different climatic regions classified by the IPCC (2006) and the four management systems T_R, NT_R, T_NR and NT_NR. 

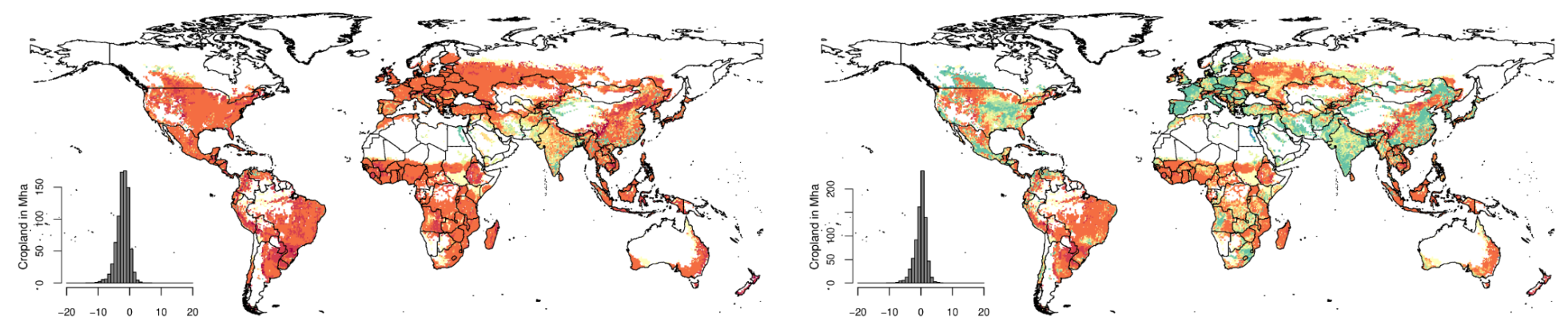

B: NT NR

D: NT_R
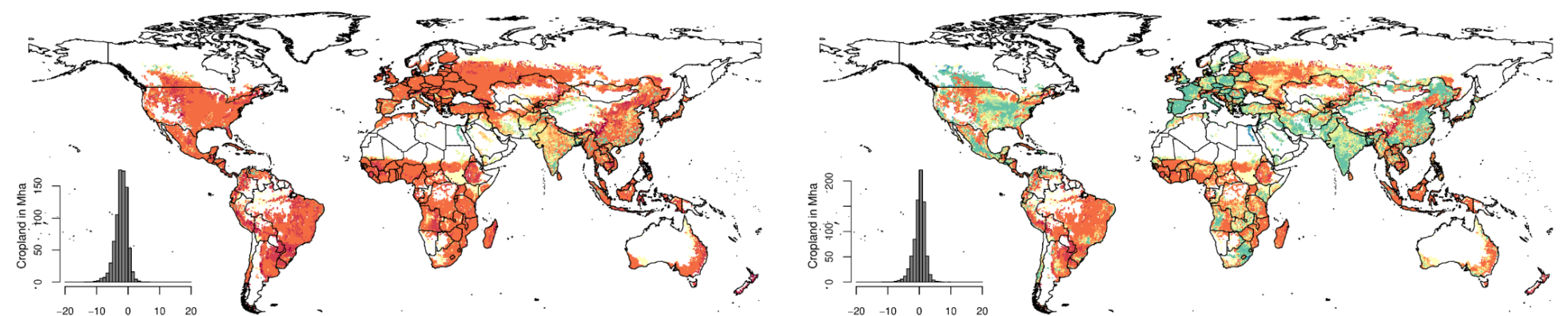

Simulated cropland SOC density change $\left(\mathrm{kg} / \mathrm{m}^{2}\right.$ ) between year 2006 and 2099 for RCP2.6 (GFDL-ESM2M)

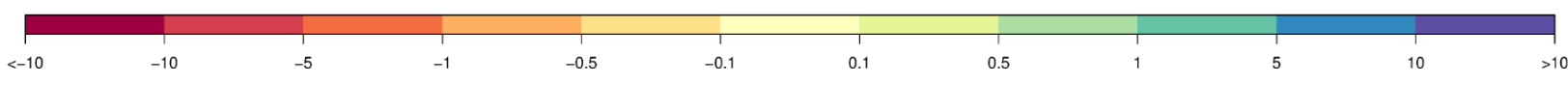

\section{Figure S7}

Simulated SOC density change between year 2006 and $2099\left(\mathrm{~kg} \mathrm{~m}^{2}\right)$ as in Fig. 4, but for RCP2.6 and GFDL_ESM2M. 

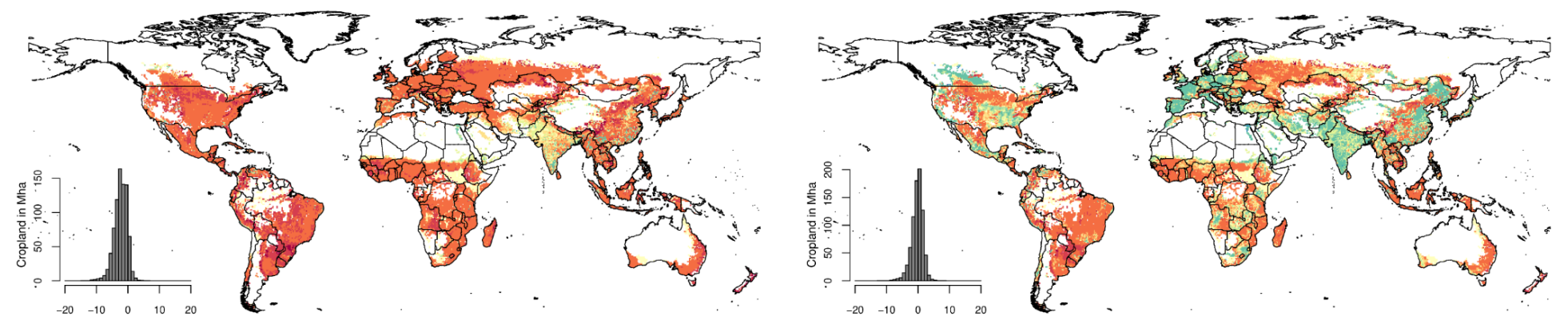

B: NT_NR

D: NT R
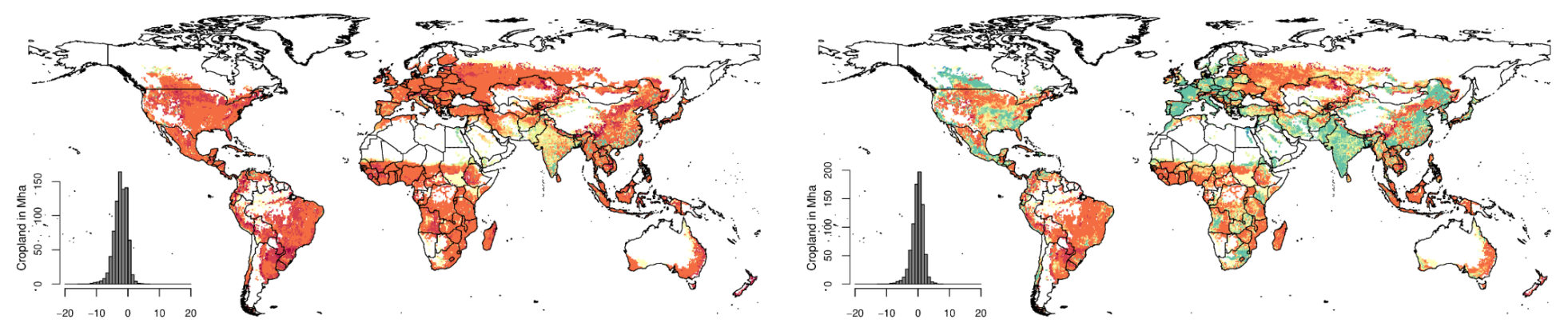

Simulated cropland SOC density change $\left(\mathrm{kg} / \mathrm{m}^{2}\right)$ between year 2006 and 2099 for RCP2.6 (IPSL-CM5A-LR)

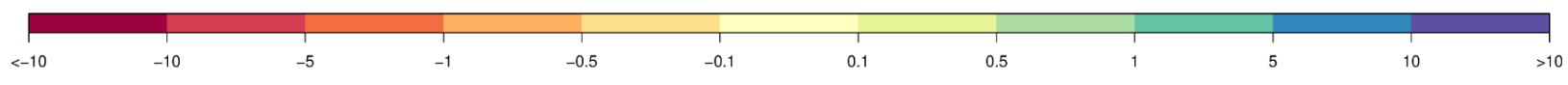

\section{Figure S8}

Simulated SOC density change between year 2006 and $2099\left(\mathrm{~kg} \mathrm{~m}^{2}\right)$ as in Fig. 4, but for RCP2.6 and IPSL-CM5A-LR. 
A: T_NR

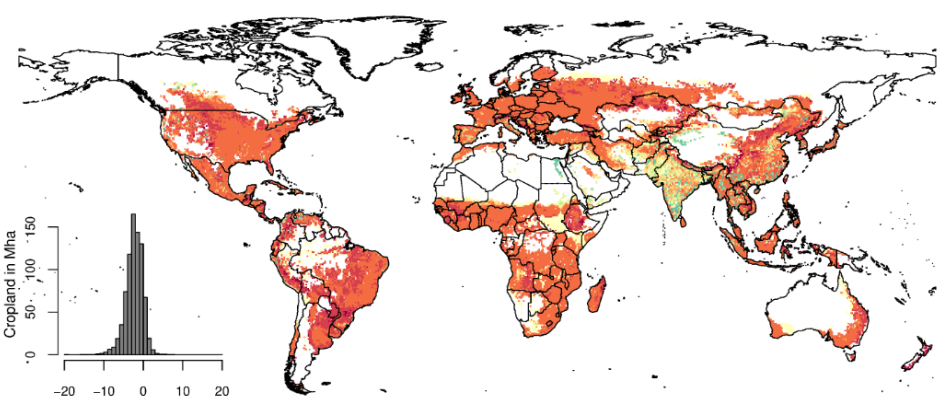

B: NT_NR

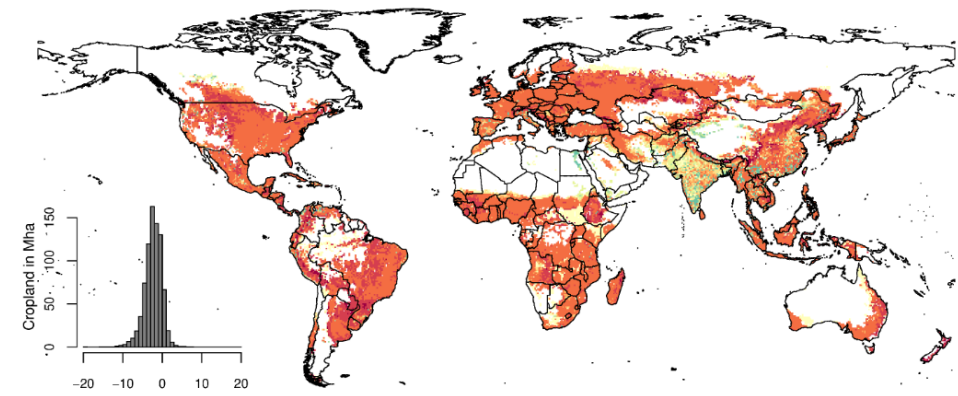

Simulated cropland SOC density change (kg/ m²) between year 2006 and 2099 for RCP2.6 (MIROC5)

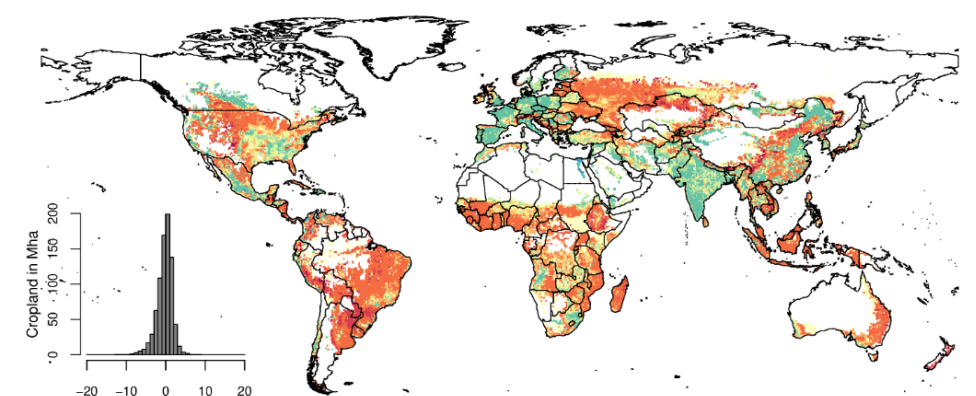

D: NT_R

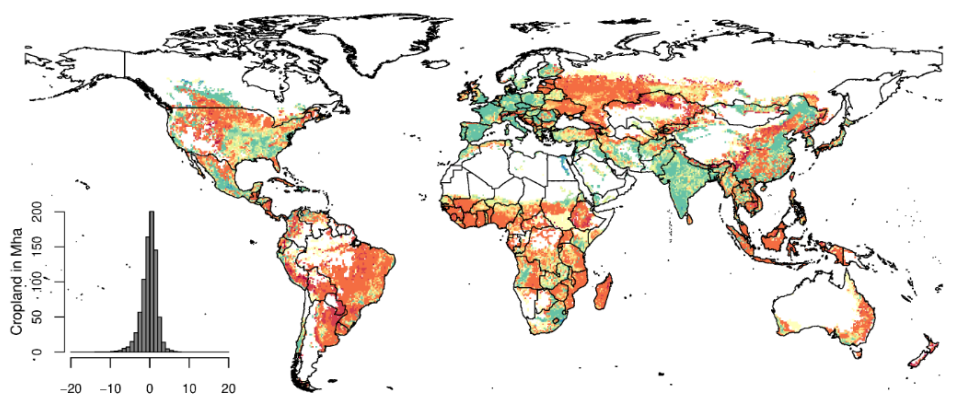

Figure S9

Simulated SOC density change between year 2006 and $2099\left(\mathrm{~kg} \mathrm{~m}^{2}\right)$ as in Fig. 4, but for RCP2.6 and MIROC5. 
A: T_NR

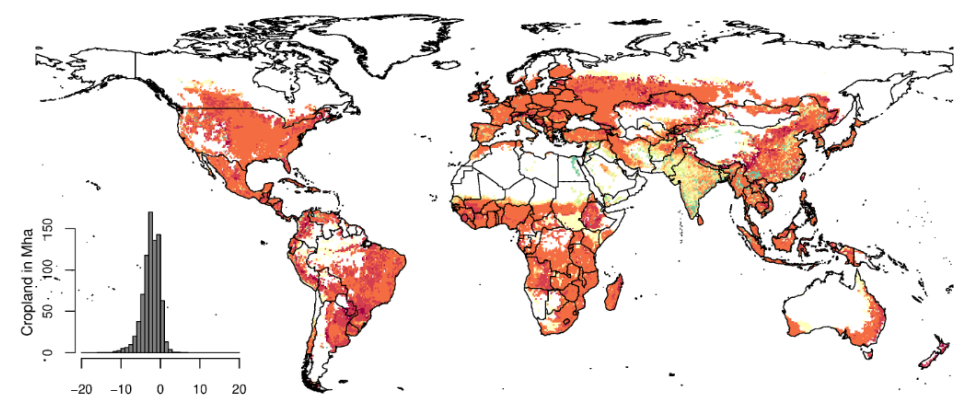

B: NT_NR

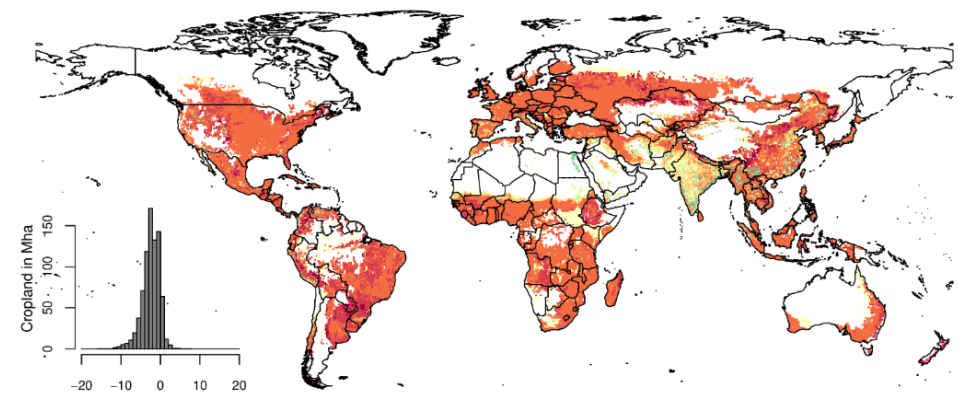

Simulated cropland SOC density change $\left(\mathrm{kg} / \mathrm{m}^{2}\right)$ between year 2006 and 2099 for RCP8.5 (HadGEM2 ES)

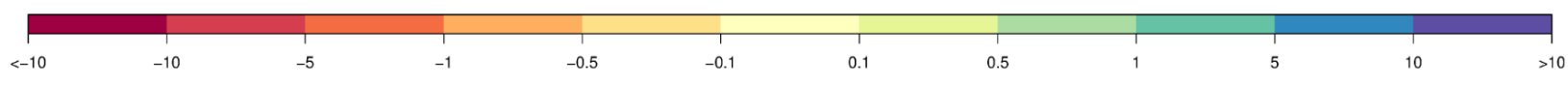

\section{Figure S10}

Simulated SOC density change between year 2006 and $2099\left(\mathrm{~kg} \mathrm{~m}^{2}\right)$ as in Fig. 4, but for RCP8.5 and HadGEM2_ES.
C: T_R

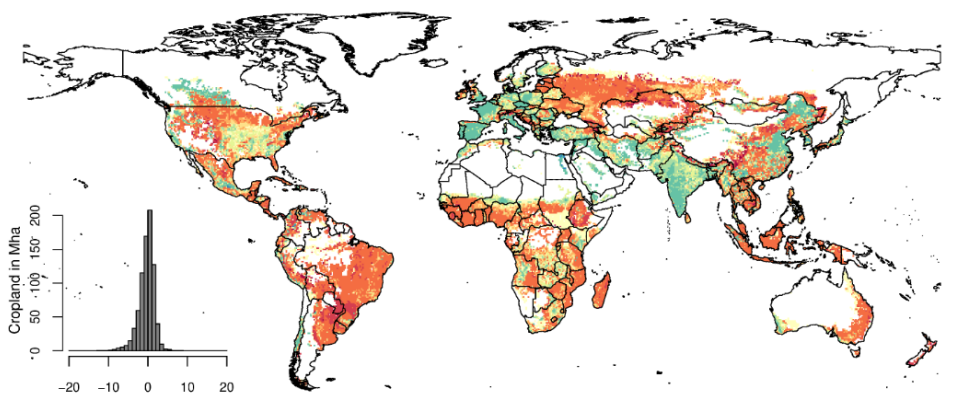

D: NT_R

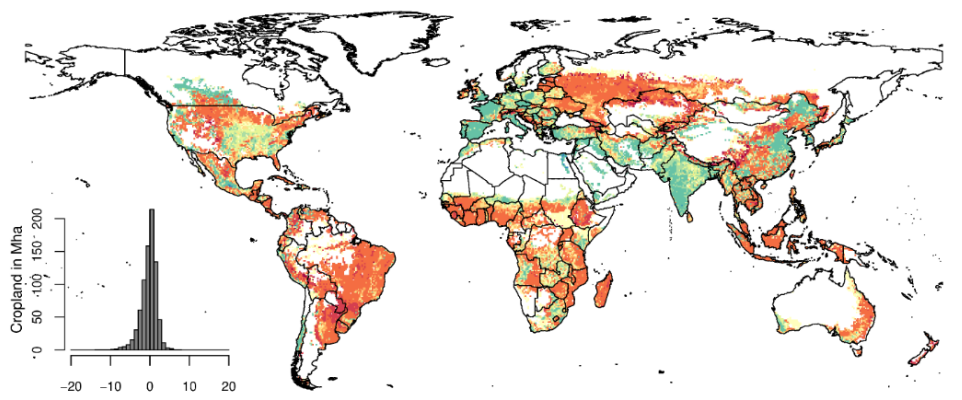


A: T_NR

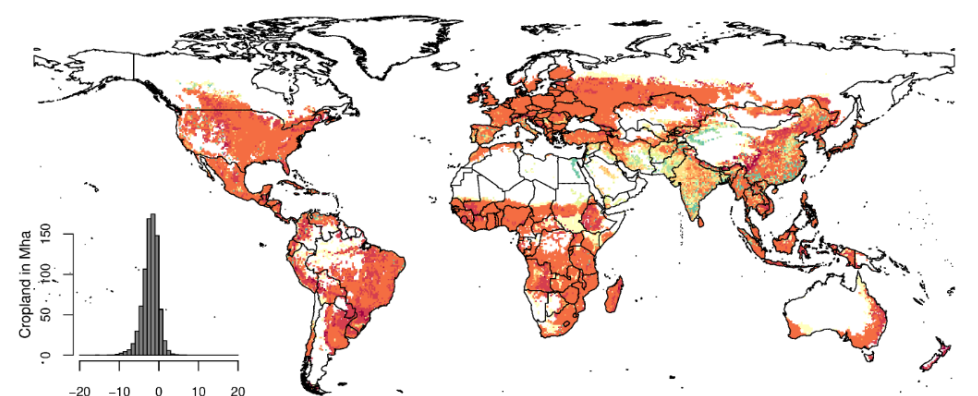

B: NT_NR

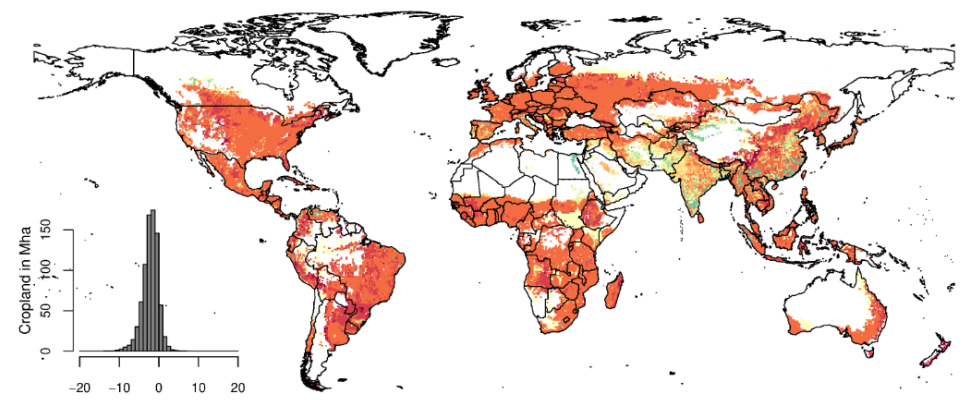

Simulated cropland SOC density change $\left(\mathrm{kg} / \mathrm{m}^{2}\right)$ between year 2006 and 2099 for RCP8.5 (GFDL-ESM2M)

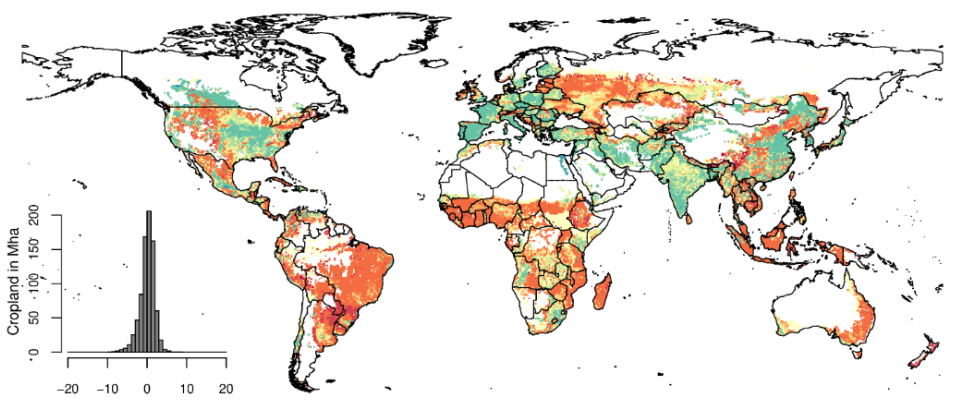

D: NT_R

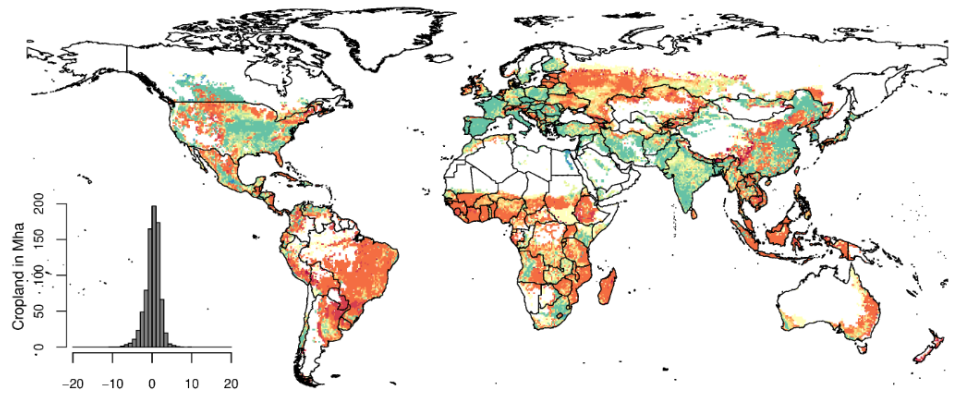

0.5

\section{Figure S11}

Simulated SOC density change between year 2006 and $2099\left(\mathrm{~kg} \mathrm{~m}^{2}\right)$ as in Fig. 4, but for RCP8.5 and GFDL-ESM2M. 
A: T NR

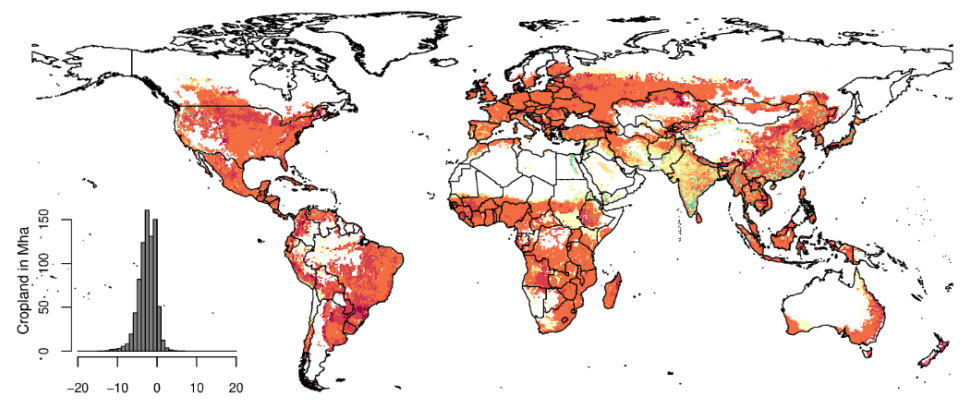

B: NT_NR

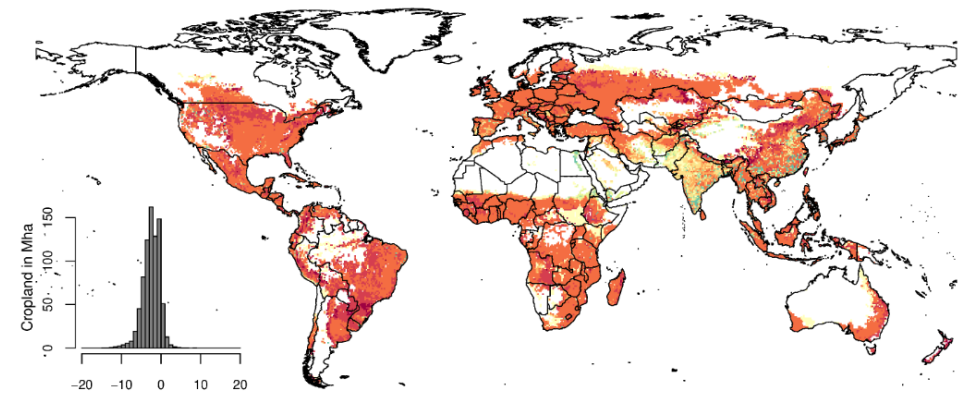

Simulated cropland SOC density change $\left(\mathrm{kg} / \mathrm{m}^{2}\right)$ between year 2006 and 2099 for RCP8.5 (IPSL-CM5A-LR)

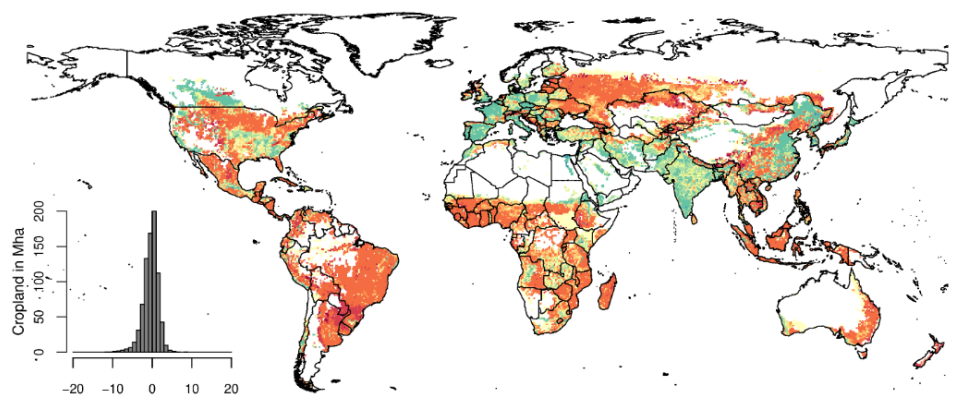

D: NT_R

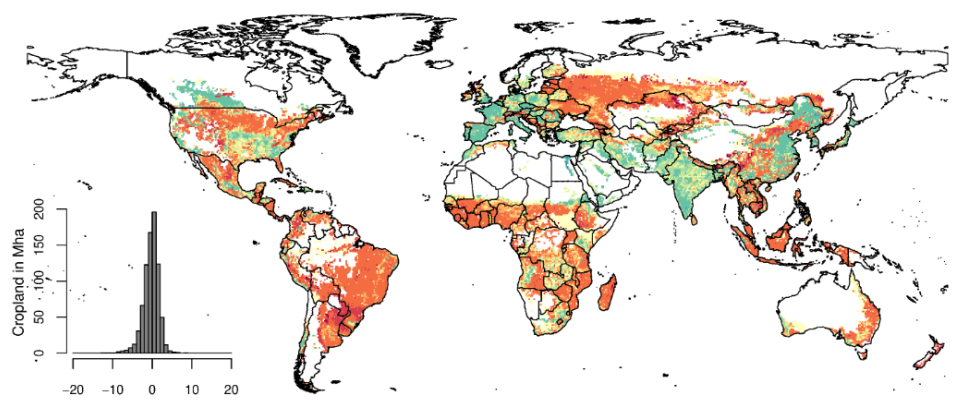

\section{Figure S12}

Simulated SOC density change between year 2006 and $2099\left(\mathrm{~kg} \mathrm{~m}^{2}\right)$ as in Fig. 4, but for RCP8.5 and IPSL-CM5A-LR. 

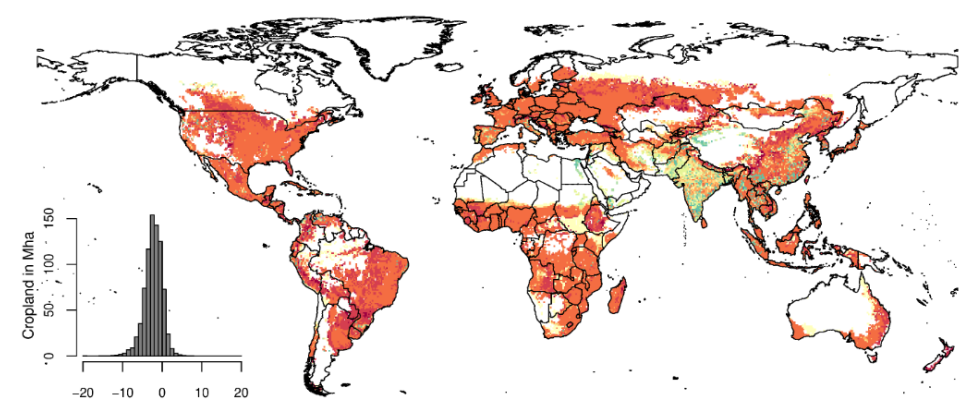

B: NT_NR
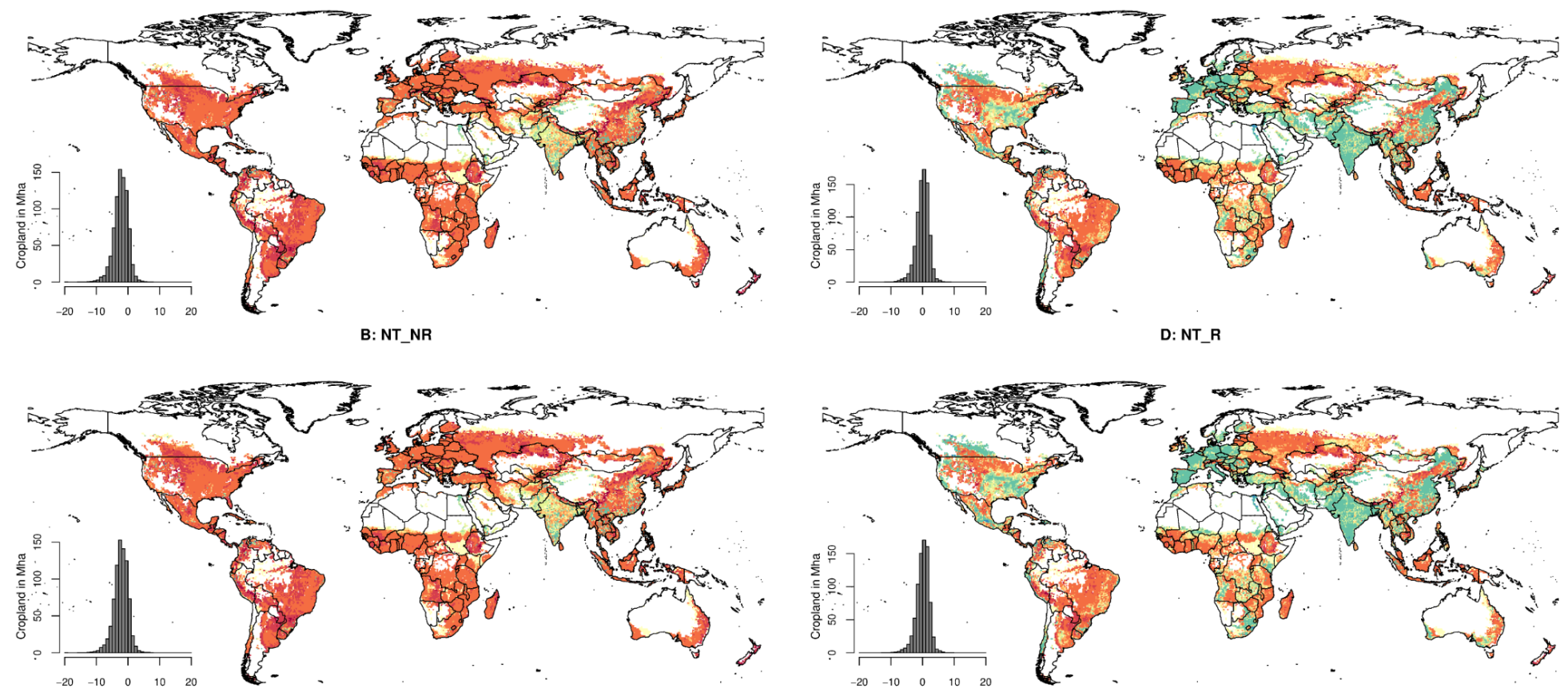

D: NT_R

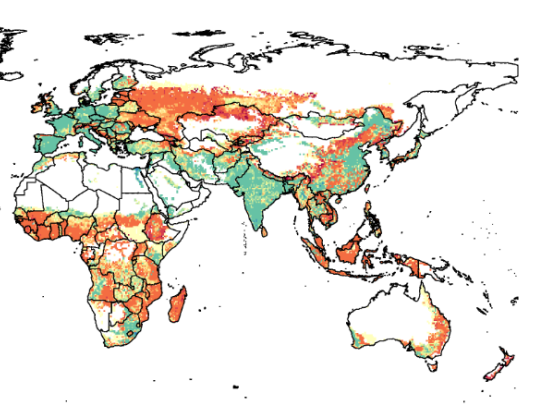

Simulated cropland SOC density change $\left(\mathrm{kg} / \mathrm{m}^{2}\right)$ between year 2006 and 2099 for RCP8.5 (MIROC5)

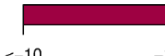

$-0.5$

0.5

\section{Figure S13}

Simulated SOC density change between year 2006 and $2099\left(\mathrm{~kg} \mathrm{~m}^{2}\right)$ as in Fig. 4, but for RCP8.5 and MIROC5. 